\title{
EXAFS investigation of low temperature nitrided stainless steel
}

Oddershede, Jette; Christiansen, Thomas; Ståhl, Kenny; Somers, Marcel A. J.

Published in:

Journal of Materials Science: Materials in Medicine

Link to article, DOI:

10.1007/s10853-008-2791-y

Publication date:

2008

Document Version

Publisher's PDF, also known as Version of record

Link back to DTU Orbit

Citation (APA):

Oddershede, J., Christiansen, T., Ståhl, K., \& Somers, M. A. J. (2008). EXAFS investigation of low temperature nitrided stainless steel. Journal of Materials Science: Materials in Medicine, 43(15), 5358-5367.

https://doi.org/10.1007/s10853-008-2791-y

\section{General rights}

Copyright and moral rights for the publications made accessible in the public portal are retained by the authors and/or other copyright owners and it is a condition of accessing publications that users recognise and abide by the legal requirements associated with these rights.

- Users may download and print one copy of any publication from the public portal for the purpose of private study or research.

- You may not further distribute the material or use it for any profit-making activity or commercial gain

- You may freely distribute the URL identifying the publication in the public portal 


\title{
EXAFS investigation of low temperature nitrided stainless steel
}

\author{
Jette Oddershede - Thomas L. Christiansen • \\ Kenny Ståhl · Marcel A. J. Somers
}

Received: 21 February 2008/ Accepted: 6 June 2008/Published online: 28 June 2008

(C) Springer Science+Business Media, LLC 2008

\begin{abstract}
Low temperature nitrided stainless steel AISI 316 flakes were investigated with EXAFS and X-ray diffraction analysis. The stainless steel flakes were transformed into a mixture of nitrogen expanded austenite and nitride phases. Two treatments were carried out yielding different overall nitrogen contents: (1) nitriding in pure $\mathrm{NH}_{3}$ and (2) nitriding in pure $\mathrm{NH}_{3}$ followed by reduction in $\mathrm{H}_{2}$. The majority of the $\mathrm{Cr}$ atoms in the stainless steel after treatment 1 and 2 was associated with a nitrogen-chromium bond distance comparable to that of the chemical compound $\mathrm{CrN}$. The possibility of the occurrence of mixed substitutionalinterstitial atom clusters or coherent nitride platelets in nitrogen-expanded austenite is discussed.
\end{abstract}

\section{Introduction}

Low temperature nitriding of austenitic (fcc) stainless steel gives rise to the dissolution of colossal quantities of nitrogen in the surface adjacent region under para-equilibrium conditions, provided that the nitriding temperature is kept below approximately $720 \mathrm{~K}$. The nitrided zone is referred to as expanded austenite or S-phase, even though essentially no new crystal structure develops. Low temperature nitriding greatly improves the tribological properties of stainless steel

J. Oddershede $\cdot$ K. Ståhl

Department of Chemistry, Technical University of Denmark, 2800 Kgs. Lyngby, Denmark

T. L. Christiansen $(\bowtie) \cdot$ M. A. J. Somers

Department of Mechanical Engineering, Technical University

of Denmark, 2800 Kgs. Lyngby, Denmark

e-mail: tc@ipl.dtu.dk without impairing the corrosion properties. Consequently, the nature of expanded austenite has attracted much focus, both scientifically and technologically [1-5].

Expanded austenite is a supersaturated solid solution of nitrogen (or carbon) in stainless steel with a homogeneity range corresponding to an occupancy of $y_{\mathrm{N}}=0.18-0.61$ of the interstitial sublattice, i.e. approximately $17-38$ at. $\% \mathrm{~N}$, respectively [6]. Such high nitrogen contents are obtained due to the high affinity between nitrogen and chromium, where nitrogen is believed to reside in the immediate vicinity of the supposed randomly distributed chromium atoms, i.e. short range order of $\mathrm{N}$ occurs. The thermodynamically more stable $\mathrm{CrN}$ does not form within typical treatment times of up to $24 \mathrm{~h}$, as a consequence of the low mobility of chromium at the nitriding temperature. Virtually only nitrogen is able to diffuse at a significant rate; thus nitrogen contents many times higher than the equilibrium solubility are attained. A fraction of the nitrogen content in expanded austenite, corresponding to $y_{\mathrm{N}}=0.18$, has been observed to be more tightly bound than nitrogen in the composition range $y_{\mathrm{N}}=0.18-0.61$; there are strong indications that the tightly bound nitrogen interacts with chromium, which leads to nitrogen trapping [6].

Extended X-ray absorption fine structure analysis (EXAFS) is a proficient tool for probing the local environment around each atom type in the metal lattice of nitrided or carburised steels. In particular the local structure of the chromium atoms is of interest in this respect, since it may shed a light on the actual occurrence of the anticipated short range ordering of nitrogen atoms. The information that can be obtained comprises bond length, disorder (thermal or static) and the number of nearest neighbours. These parameters can be related to the presence/absence of interstitially dissolved elements in the immediate surroundings of the probed metal atom. 
Published EXAFS investigations of short range order of nitrogen in stainless steel are scarce [7-9]. The investigation by Oda et al. [7] addressed nitrogen bearing $15 \mathrm{Ni}-$ $15 \mathrm{Cr}$ austenitic stainless steel, which means nitrogen contents many times lower than for expanded austenite. The nitrogen atoms were found to form interstitial-substitutional complexes with chromium atoms. Kizler et al. [8] investigated conventionally salt bath nitrided foils of stainless steel AISI 304 and AISI 316. Unfortunately, neither nitriding temperature nor duration of nitriding is stated in this work. However, conventional nitriding is carried out at temperatures above $763 \mathrm{~K}$ and most likely close to $853 \mathrm{~K}$, i.e. in a temperature range where precipitation of $\mathrm{CrN}$ occurs readily. In the work by Kizler et al. it was reported that a strong lattice distortion was found around the $\mathrm{Cr}$ and Mo atoms, whereas only small lattice distortions could be observed in the neighbourhood of the $\mathrm{Fe}$ and $\mathrm{Ni}$ atoms. This observation was interpreted to indicate that nitrogen would prefer $\mathrm{Cr}$ and $\mathrm{Mo}$ as nearest neighbours, which would be consistent with the higher affinity of nitrogen for $\mathrm{Cr}$ and Mo as compared to $\mathrm{Fe}$ and $\mathrm{Ni}$. In the case that nitrides of $\mathrm{Cr}$ and Mo have formed this is trivial. A recent investigation was carried out by MunozPaez et al. [9] on nitrided Cr, Mo, Mn and V alloyed ferritic steels. The authors state the occurrence of "new noncrystalline domains involving nitrogen", although there appears to be a striking resemblance to older work by Jack and co-workers on mixed substitutional-interstitial atom cluster formation in low alloyed ferritic steels (e.g. [10]). The quantitative analysis showed that "the majority of the $\mathrm{V}, \mathrm{Mn}$, and $\mathrm{Cr}$ atoms form interstitial nitrides in which the nitrogen atoms are located in octahedral holes" [9], while a small fraction $(1 / 4-1 / 3)$ of the metal centers was found to retain the ferritic bcc structure.

In the present investigation $\mathrm{Cr}$ - and $\mathrm{Fe}-\mathrm{K}$ edge EXAFS analysis was carried out on low temperature nitrided micrometer-sized AISI 316 stainless steel flakes.

\section{Experimental and methods}

\section{Nitriding}

The stainless steel AISI 316 flakes with thickness 0.4-1.2 $\mu \mathrm{m}$ (325 mesh) were austenitised prior to nitriding by heating them at a rate of $30 \mathrm{~K} / \mathrm{min}$ to $1,363 \mathrm{~K}$ in an atmosphere of flowing $\mathrm{H}_{2}(99.999 \%)$ followed by immediate cooling at a rate of $50 \mathrm{~K} / \mathrm{min}$ to the nitriding temperature. This annealing procedure ensured a full transformation of the cold worked flakes into austenite. Furthermore, the reducing hydrogen atmosphere removes the passive layer, consisting mainly of chromium(hydr)oxide, thus enabling subsequent nitriding of the flakes.
Nitriding was carried out in a Netzsch STA449 simultaneous thermal analyser for continuous monitoring of the sample weight. The nitriding temperature was $718 \mathrm{~K}$ and nitriding was continued until a stationary weight gain was reached, suggesting that a para-equilibrium between nitrogen in the gas phase and in the stainless steel had been reached for the adjusted gas composition. The gas consisted of 9 vol. $\% \mathrm{~N}_{2}$ and 91 vol. $\% \mathrm{NH}_{3}$, which corresponds to an infinitely high nitrogen activity (according to the dissociation equilibrium of ammonia). It was observed experimentally that the flakes had to be exposed to the nitriding gas for $24 \mathrm{~h}$ before a stationary sample weight was obtained. As compared to nitriding of stainless steel foils, where the surface can be activated by chemical dissolution of the passive chromium(hydr)oxide film followed by subsequent deposition of a $\mathrm{Ni}$ film of a few nanometers [6], the nitriding of the present samples proceeds rather sluggish. The reason for this could be that the $\mathrm{H}_{2}$ activation at high temperature used in the present investigation is sensitive to surface pollution, which will slow down the kinetics of nitrogen uptake. Furthermore, the flakes are produced by a ball milling method using organic lubricants, which can pollute the surface and make surface activation more difficult. However, the flakes have the advantage that "large" quantities of nitrided material can be produced compared to the method applied in Ref. [6], and the thickness of the flakes ensures that the occurrence of composition-induced stresses can be excluded.

Nitriding under the above described conditions should give rise to a full transformation of austenite into nitrogen expanded austenite having an interstitial occupancy of $y_{\mathrm{N}}=0.61$ [6]. However, the overall nitrogen content in the as-nitrided sample (stationary nitrogen uptake) corresponded to $y_{\mathrm{N}}=0.51$. Part of the batch of as-nitrided flakes was exposed to flowing hydrogen at $718 \mathrm{~K}$ for $3 \mathrm{~h}$. This so-called denitriding (see Ref. [6] for further details) resulted in removal of loosely bound nitrogen atoms until a stationary nitrogen content was obtained. During thermal exposure at $1,363 \mathrm{~K}$ the (de)nitrided flakes were partly sintered together in the crucibles, which necessitated modest mechanical processing in order to obtain a homogenous batch of powdered flakes for characterisation with EXAFS and X-ray diffraction (XRD).

X-ray diffraction analysis and Rietveld refinements

The XRD data were collected using a Bruker D8 AXS diffractometer equipped with a $\mathrm{Cr}$ anode $\left(\lambda\left(\mathrm{CrK} \alpha_{1}\right)=\right.$ $2.28962 \AA, \lambda\left(\mathrm{CrK} \alpha_{2}\right)=2.29352 \AA$ operating in BraggBrentano mode.

The different phases in the XRD patterns were identified by means of search-match. In the subsequent Rietveld refinements the following parameters were refined: a scale 
factor, a Voigt peak profile parameter and lattice constants for each phase besides an overall $2 \theta$ zero shift and 3 Chebyshev background parameters. This gave a total of 18 parameters for both samples. The thermal parameters were set to $B_{\mathrm{Cr}}=B_{\mathrm{Fe}}=B_{\mathrm{N}}=1.0 \AA^{2}$ for all phases.

For the expanded austenite phase an extra Voigt peak profile parameter coupled to the $<111>$ direction was refined to account for the observed peak width anisotropy. This peak width anisotropy cannot be the result of anisotropic particle shapes, because the $\{111\}$ planes are found in four different orientations throughout the crystal due to the cubic space group symmetry. Rather it has been argued to result from the presence of deformation stacking faults and screw dislocations in the structure [11].

In order to limit the number of parameters the nitrogen contents in the expanded austenite phases were not refined, but were calculated from the lattice parameter $a=3.6396$ $+0.59724 y_{\mathrm{N}}$ as determined in Ref. [6]. For the denitrided sample the lattice parameter was outside the interval for which the linear relationship between $a$ and $y_{\mathrm{N}}$ was determined, so the value of $y_{\mathrm{N}}=0.12$ was estimated from an extrapolation towards the $\left(y_{\mathrm{N}}, a\right)$ pairs determined for $y_{\mathrm{N}}$ below 0.10 . Finally the nitrogen contents of the martensite phase in the denitrided sample was set to 2 atoms $\mathrm{N}$ per 100 Fe atoms based on the $c / a$ ratio [12].

\section{EXAFS analysis}

$\mathrm{Cr}$ and $\mathrm{Fe}$ K-edge EXAFS data were collected in transmission mode at MAX-lab beamline I811 equipped with a Si[111] double crystal monochromator [13]. Detuning to remove higher harmonics was performed. The samples were mounted on two pieces of tape, and the acquisition time was 70 min per scan.
The analysis of the EXAFS data was performed in the WinXAS program [14]. For each sample 2-5 scans of the absorption as a function of energy, $\mu(E)$, were averaged after energy calibrations performed using the $E_{0}$ values tabulated for $\mathrm{Cr}$ and $\mathrm{Fe}$. Standard procedures were then used for the background subtraction, normalisation and spline fitting. At this point the EXAFS function $\chi(k)$, giving the modulation in the absorbance of the central atom as a function of the photoelectron wavevector $k$, where $k$ is proportional to $\left(E-E_{0}\right)^{1 / 2}$, was obtained. Finally $k^{3} \chi(k)\left(k^{3}\right.$ weighting used to avoid information loss at high $k$-values) was Fourier Transformed into (real) R-space to yield the pseudo radial distribution function, which gives the relative probability of finding neighbouring atoms with a given distance to the central atom. The $k$-ranges used for the spline fittings and for the Fourier Transforms of $k^{3} \chi(k)$ are given in Tables 1 and 2 .

The phase and amplitude parameters used for the modelling of the EXAFS data, which was performed in R-space, were obtained by ab initio calculations using the program FEFF7 [15]. All samples were assumed to consist of one or two cubic phase(s). In this way the crystallographic symmetry could be used to correlate the values of $r_{\mathrm{j}}$ together so that only one parameter, namely the cell constant which can easily be compared with tabulated values, was refined for each phase. Note that for the twophase models the relative abundance of the phases must be input as fixed values that cannot be refined. Letting $\mathrm{M}$ denote either $\mathrm{Cr}$ or $\mathrm{Fe}$, only paths corresponding to the first $\mathrm{M}-\mathrm{N}$ shell (if present) and the first four $\mathrm{M}-\mathrm{M}$ distances were added during the modelling. If a 3-atom multiple scattering path of the same $r_{\mathrm{j}}$ as the M-M path and a much higher value of $\left|f^{\mathrm{eff}}{ }_{\mathrm{j}}\right|$ was found, this path was used on behalf of the M-M path to improve the fits significantly.
Table 1 Cr EXAFS refinement data; coordination numbers $\left(N_{\mathrm{j}}\right)$, distances $\left(r_{\mathrm{j}}\right)$, Debye-Waller factors $\left(\sigma_{\mathrm{j}}^{2}\right)$, energy scale offset $\left(\Delta E_{0}\right)$, amplitude reduction factor $\left(S_{0}^{2}\right)$, residual $(R)$, and $k$ ranges for spline fitting and Fourier Transformation (FT)

\begin{tabular}{|c|c|c|c|c|c|c|}
\hline Path & $N_{\mathrm{j}}$ & $r_{\mathrm{j}}(\AA)$ & $\sigma_{\mathrm{j}}^{2}\left(\AA^{2}\right)$ & $\Delta E_{0}(\mathrm{eV})$ & $S_{0}^{2}$ & $R$ \\
\hline \multicolumn{7}{|l|}{ As-nitrided } \\
\hline Chromium nitride & & $\mathrm{CrN}(\mathrm{F} \mathrm{m} 3 \mathrm{~m})$ & & & & \\
\hline $\mathrm{Cr}-\mathrm{N}$ & 6 & 2.06 & 0.0071 & \multirow[t]{3}{*}{-0.35} & \multirow[t]{3}{*}{1} & \multirow[t]{5}{*}{10.0} \\
\hline $\mathrm{Cr}-\mathrm{Cr}$ & 12 & 2.91 & 0.0129 & & & \\
\hline $\mathrm{Cr}-\mathrm{Cr}-\mathrm{N}$ & 12 & 4.12 & 0.0197 & & & \\
\hline $\mathrm{Cr}-\mathrm{Cr}$ & 24 & 5.05 & 0.0197 & \multicolumn{2}{|c|}{ Spline: $0.5-13.8 \AA^{-1}$} & \\
\hline $\mathrm{Cr}-\mathrm{Cr}-\mathrm{Cr}$ & 24 & 5.95 & 0.0209 & \multicolumn{2}{|c|}{ FT: $3.0-11.0 \AA^{-1}$} & \\
\hline \multicolumn{7}{|l|}{ Denitrided } \\
\hline \multicolumn{2}{|l|}{ Chromium nitride } & \multicolumn{2}{|l|}{$\mathrm{CrN}(\mathrm{F}$ m 3 m) } & & & \\
\hline $\mathrm{Cr}-\mathrm{N}$ & 6 & 2.07 & 0.0080 & -0.25 & 1 & 12.0 \\
\hline $\mathrm{Cr}-\mathrm{Cr}$ & 12 & 2.92 & 0.0138 & & & \\
\hline $\mathrm{Cr}-\mathrm{Cr}-\mathrm{N}$ & 12 & 4.13 & 0.0181 & & & \\
\hline $\mathrm{Cr}-\mathrm{Cr}$ & 24 & 5.06 & 0.0168 & \multicolumn{3}{|c|}{ Spline: $0.5-13.8 \AA^{-1}$} \\
\hline $\mathrm{Cr}-\mathrm{Cr}-\mathrm{Cr}$ & 24 & 5.96 & 0.0183 & \multicolumn{2}{|c|}{ FT: $3.0-11.0 \AA^{-1}$} & \\
\hline
\end{tabular}


Table 2 Fe EXAFS refinement data, for explanation of symbols see the caption of Table 1

\begin{tabular}{|c|c|c|c|c|c|c|}
\hline Path & $N_{\mathrm{j}}$ & $r_{\mathrm{j}}(\AA)$ & $\sigma_{\mathrm{j}}^{2}\left(\AA^{2}\right)$ & $\Delta E_{0}(\mathrm{eV})$ & $S_{0}^{2}$ & $R$ \\
\hline \multicolumn{7}{|l|}{ As-nitrided } \\
\hline \multicolumn{2}{|c|}{ Expanded austenite } & \multicolumn{2}{|l|}{$\gamma-\mathrm{FeN}_{0.32}(\mathrm{~F}-43 \mathrm{~m})$} & & & \\
\hline $\mathrm{Fe}-\mathrm{N}$ & 1.9 & 1.93 & 0.0064 & 6.54 & 1 & 11.9 \\
\hline $\mathrm{Fe}-\mathrm{Cr}$ & 12 & 2.73 & 0.0192 & & & \\
\hline $\mathrm{Fe}-\mathrm{Fe}-\mathrm{N}$ & 3.8 & 3.86 & 0.0173 & & & \\
\hline $\mathrm{Fe}-\mathrm{Fe}$ & 24 & 4.73 & 0.0281 & Spline: 0.2 & $0 \AA^{-1}$ & \\
\hline $\mathrm{Fe}-\mathrm{Fe}-\mathrm{Fe}$ & 24 & 5.45 & 0.0368 & FT: $4.2-13$ & & \\
\hline \multicolumn{7}{|l|}{ Denitrided } \\
\hline \multicolumn{2}{|l|}{ Ferrite } & \multicolumn{2}{|l|}{$\alpha-\mathrm{Fe}(\mathrm{I} \mathrm{m} 3 \mathrm{~m})$} & & & \\
\hline $\mathrm{Fe}-\mathrm{Fe}$ & 3.38 & 2.50 & 0.0069 & 7.45 & 1 & 8.7 \\
\hline $\mathrm{Fe}-\mathrm{Fe}$ & 2.54 & 2.89 & 0.0110 & & & \\
\hline $\mathrm{Fe}-\mathrm{Fe}$ & 5.07 & 4.08 & 0.0116 & & & \\
\hline $\mathrm{Fe}-\mathrm{Fe}$ & 10.14 & 4.79 & 0.0087 & & & \\
\hline \multicolumn{2}{|l|}{ Austenite } & \multicolumn{2}{|l|}{$\gamma-\mathrm{Fe}(\mathrm{F}-43 \mathrm{~m})$} & & & \\
\hline $\mathrm{Fe}-\mathrm{Fe}$ & 6.93 & 2.54 & 0.0207 & & & \\
\hline $\mathrm{Fe}-\mathrm{Fe}$ & 3.46 & 3.59 & 0.0215 & \multicolumn{3}{|c|}{ Spline: $0.2-16.0 \AA^{-1}$} \\
\hline $\mathrm{Fe}-\mathrm{Fe}$ & 13.86 & 4.40 & 0.0283 & \multicolumn{2}{|c|}{ FT: $3.3-14.9 \AA^{-1}$} & \\
\hline
\end{tabular}

Besides the cubic lattice constant(s), $\Delta E_{0}$ and the values of $\sigma_{\mathrm{j}}^{2}$ were refined. $S_{0}^{2}=1$ was maintained for all refinements, because no literature values for similar systems were found.

The above described refinement procedure gave between 6 and 9 free variables (Tables 1 and 2), a number which is well below the maximum that can be justified by the quality of the data. It should be noted that both small deviations from the assumed cubic symmetries and the presence of additional phases with a similar local structure will result in increased values of $\sigma_{\mathrm{j}}^{2}$, and that large values of $\sigma_{\mathrm{j}}^{2}$ are in fact observed for all EXAFS refinements (Tables 1 and 2).

\section{Results and interpretations}

XRD and Rietveld refinements

The recorded diffractograms are shown in Figs. 1 and 2 along with the diffraction patterns of the different phases from the Rietveld refinements. For each sample four phases were identified. The mass percentages of these phases were derived from the scale factors and are given along with the refined cell constants and final $R$-values of the Rietveld refinements in Table 3 . The corresponding nitrogen balances of the entire samples, determined from the mass fractions, are given in Table 4 . For both samples investigated it is noted
Fig. $1 \mathrm{X}$-ray diffraction pattern and Rietveld refinement of the as-nitrided sample showing the contributions of the identified phases along with the peak positions and the difference curve (same scale)

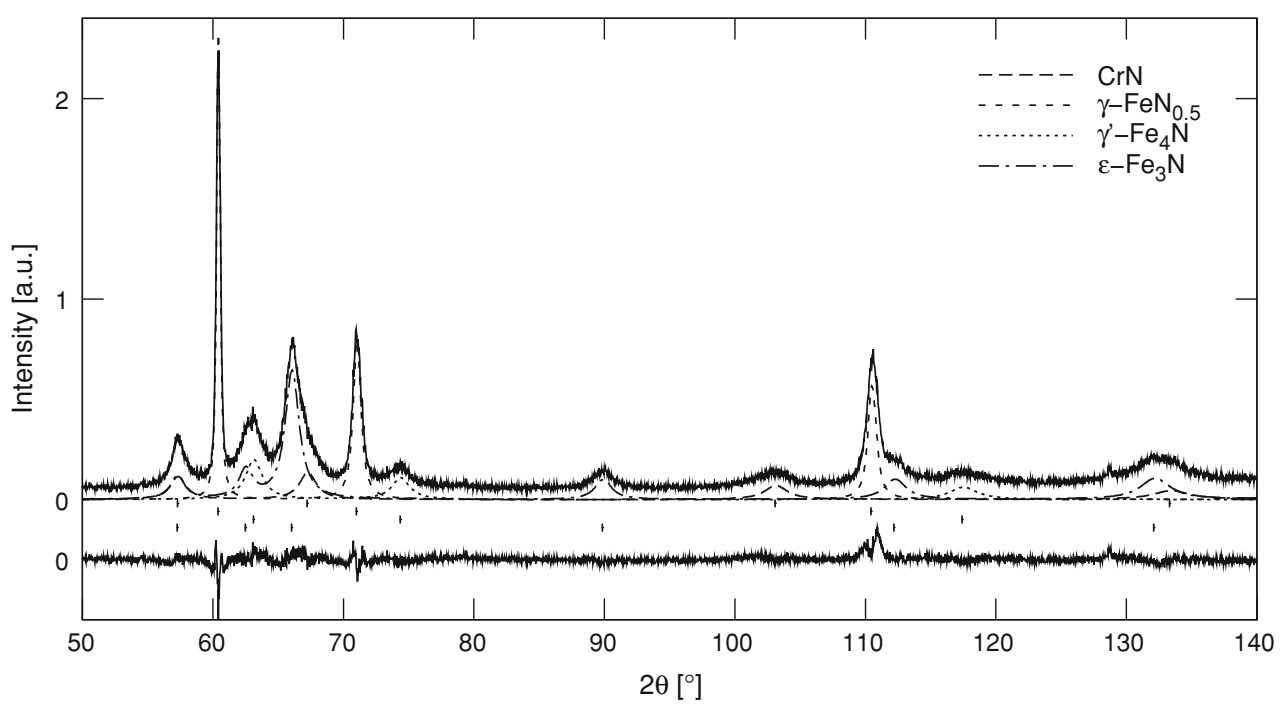




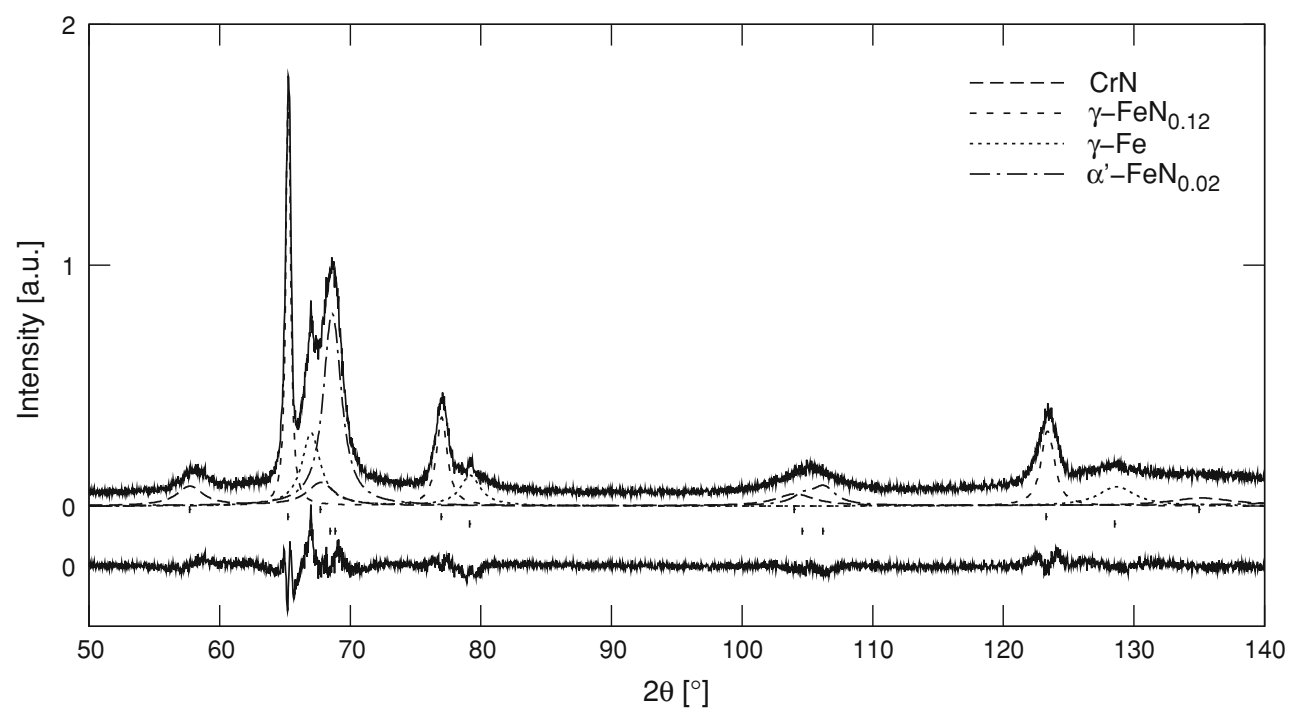

Fig. 2 X-ray diffraction pattern and Rietveld refinement of the denitrided sample showing the contributions of the identified phases along with the peak positions and the difference curve (same scale)

Table 3 Structures and mass fractions of the phases identified by means of Rietveld refinement

\begin{tabular}{|c|c|c|c|c|}
\hline Phase & Chromium nitride & Expanded austenite & Iron nitride & Iron nitride \\
\hline As-nitrided & \multicolumn{4}{|l|}{$R=0.0883$} \\
\hline Formula & $\mathrm{CrN}$ & $\gamma-\mathrm{FeN}_{0.5}$ & $\gamma^{\prime}-\mathrm{Fe}_{4} \mathrm{~N}$ & $\varepsilon-\mathrm{Fe}_{3} \mathrm{~N}$ \\
\hline Space group & $\mathrm{F} \mathrm{m} 3 \mathrm{~m}$ & $\mathrm{~F}-43 \mathrm{~m}$ & $\mathrm{P} m-3 \mathrm{~m}$ & P 312 \\
\hline$a(\AA)$ & $4.1356(8)$ & $3.9425(2)$ & $3.7892(7)$ & $4.7784(13)$ \\
\hline$c(\AA)$ & & & & $4.4141(8)$ \\
\hline Mass fraction & $0.112(3)$ & $0.388(3)$ & $0.137(3)$ & $0.363(4)$ \\
\hline Phase & Chromium nitride & Expanded austenite & Austenite & Martensite \\
\hline Denitrided & \multicolumn{4}{|l|}{$R=0.0912$} \\
\hline Formula & $\mathrm{CrN}$ & $\gamma-\mathrm{FeN}_{0.12}$ & $\gamma-\mathrm{Fe}$ & $\alpha-\mathrm{FeN}_{0.02}$ \\
\hline Space group & $\mathrm{F} \mathrm{m} 3 \mathrm{~m}$ & $\mathrm{~F}-43 \mathrm{~m}$ & $\mathrm{~F}-43 \mathrm{~m}$ & I $4 / \mathrm{m} \mathrm{m} \mathrm{m}$ \\
\hline$a(\AA)$ & $4.1100(15)$ & $3.6796(3)$ & $3.5944(6)$ & $2.8635(6)$ \\
\hline$c(\AA)$ & & & & $2.8933(13)$ \\
\hline Mass fraction & $0.135(4)$ & $0.301(4)$ & $0.199(5)$ & $0.366(5)$ \\
\hline
\end{tabular}

Table 4 Overall nitrogen contents expressed as atoms $\mathrm{N}$ per metal atom as determined by various methods

\begin{tabular}{llll}
\hline & Thermogravimetry & Rietveld refinement & EXAFS \\
\hline As-nitrided & 0.51 & 0.46 & 0.45 \\
Denitrided & - & 0.17 & 0.19 \\
\hline
\end{tabular}

that, generally, the diffraction peaks are very broad, except for the 111 peak of expanded austenite. Many factors besides the particle size are likely to contribute to this observed broadening, as for instance composition and/or lattice strain variations, i.e. microstresses. It has been shown that the presence of deformation stacking faults and screw dislocations in expanded austenite has an influence on the line profiles [11].

\section{As-nitrided sample}

The major component of the as-nitrided sample was identified as expanded austenite with a composition corresponding to $y_{\mathrm{N}}=0.50$, as followed from the lattice parameter dependence on nitrogen content [2]. $\mathrm{CrN}$ was identified in the as-nitrided sample with a mass fraction of 0.112. For comparison, the formation of $\mathrm{CrN}$ incorporating all $\mathrm{Cr}$ atoms present in the alloy would lead to a $\mathrm{CrN}$ mass fraction of 0.19. Expanded austenite and $\mathrm{CrN}$ comprise half of the total mass. The remainder was found to consist of the 
iron nitrides; fcc $\gamma^{\prime}-\mathrm{Fe}_{4} \mathrm{~N}_{1-\mathrm{X}}$, and hcp $\varepsilon-\mathrm{Fe}_{2} \mathrm{~N}_{1-\mathrm{X}}$, where $\mathrm{Ni}$ and $\mathrm{Cr}$ are likely to partly replace $\mathrm{Fe}$ in $\gamma^{\prime}$ and $\varepsilon$, respectively.

\section{Denitrided sample}

For the denitrided sample the phase with the largest mass fraction was found to be bct martensite. Mechanical deformation of expanded austenite with a relatively low interstitial nitrogen content is known to result in martensite upon deformation as a consequence of the metastability of austenite at low temperatures [16]. Mechanical deformation was introduced on removing the samples from the thermal analyser, and was necessary because the flakes had sintered together during nitriding. In addition to martensite two austenite phases were identified. Judging from the lattice constants one phase is nitrogen-free austenite and the other is nitrogen expanded austenite with $y_{\mathrm{N}}=0.12$. The final phase is $\mathrm{CrN}$. The mass fraction of $\mathrm{CrN}$ was determined to be 0.135 , while the theoretical mass fraction corresponding to a total formation of $\mathrm{CrN}$ is 0.205 .

\section{EXAFS analysis}

From Fig. 3, it can be seen that the chemical surroundings of $\mathrm{Cr}$ are identical for the as-nitrided and denitrided samples, while the environment of the $\mathrm{Fe}$ atoms is found to vary substantially with the nitrogen contents as illustrated in Fig. 4. From the FT of the EXAFS data in Fig. 5 it can be seen that the $\mathrm{Fe}$ atoms in the denitrided sample are found in nitrogen-free surroundings, whereas the octahedral interstices around the $\mathrm{Fe}$ atoms in the as-nitrided sample are partly occupied. As opposed to this the $\mathrm{Cr}$

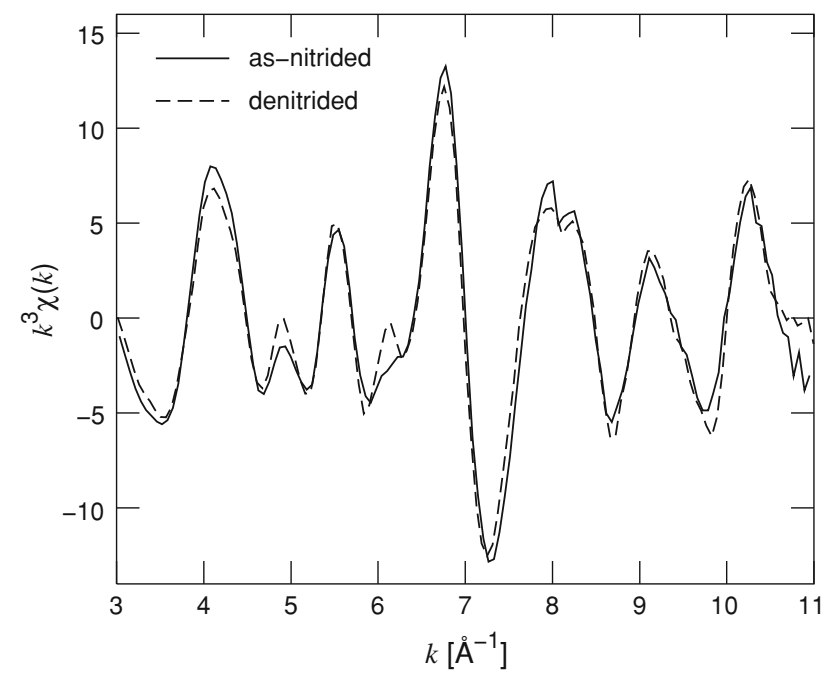

Fig. $3 k^{3}$-Weighted Cr K-edge EXAFS for the as-nitrided (full drawn line) and denitrided (dashed line) samples which display similar chromium surroundings

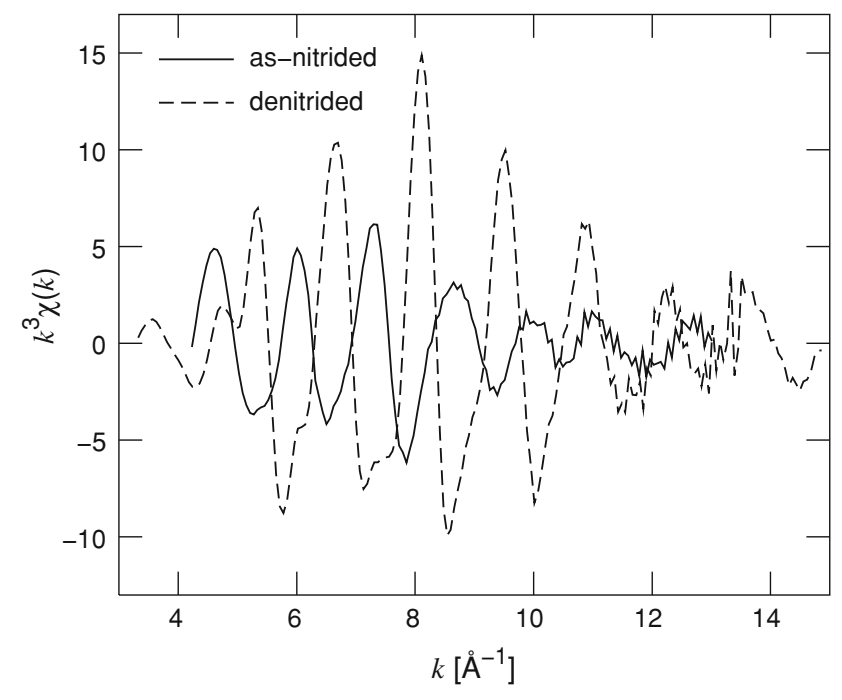

Fig. $4 k^{3}$-Weighted Fe K-edge EXAFS for the as-nitrided (full drawn line) and denitrided (dashed line) samples showing a significant difference in the iron environments

atoms are found in nitrogen saturated surroundings for both samples. Thus the EXAFS data are consistent with a higher affinity of nitrogen towards $\mathrm{Cr}$ than towards $\mathrm{Fe}$.

\section{Chromium}

The quality of the fit to the Cr EXAFS data with a single cubic phase (Fig. 5a and b) suggests that for both samples the majority of the $\mathrm{Cr}$ atoms is present in an environment identical to or reminiscent of $\mathrm{CrN}$. The lattice constant refines to $4.12-4.13 \AA$ as compared to the literature value of 4.1480(5) $\AA$ [13], while the refined values of $\sigma_{\mathrm{j}}^{2}$ are all on the large side of the acceptable level. The differences in the $\mathrm{Cr}$ environments determined by EXAFS for the nitrided and denitrided samples are within the uncertainties of the method. If $r_{\mathrm{j}}$ of the outermost shell was constrained to the $\mathrm{CrN}$ lattice constant, the corresponding value of $\sigma_{\mathrm{j}}^{2}$ became extremely large and the quality of the fit decreased dramatically. This value of $r_{\mathrm{j}}$ was therefore refined freely. All these observations indicate that a (small) fraction of the $\mathrm{Cr}$ atoms is found in chemical surroundings that are different from those identical to (or reminiscent of) CrN. Possibly within the expanded austenite, in the interface adjacent regions of the extremely small $\mathrm{CrN}$ particles or in the hcp $\varepsilon-(\mathrm{Fe}, \mathrm{Cr})_{2} \mathrm{~N}_{1-X}$ of the as-nitrided sample. These findings are consistent with the Rietveld refinement, which gave $\mathrm{CrN}$ mass fractions corresponding to binding of two-thirds of all $\mathrm{Cr}$ atoms in $\mathrm{CrN}$.

A two-phase model using the structures of $\mathrm{CrN}$ and expanded austenite in a 2:1 ratio, as suggested by XRD, was tested for the Cr EXAFS data. The obtained fits were marginally better than the single-phase fits, thus it is likely 


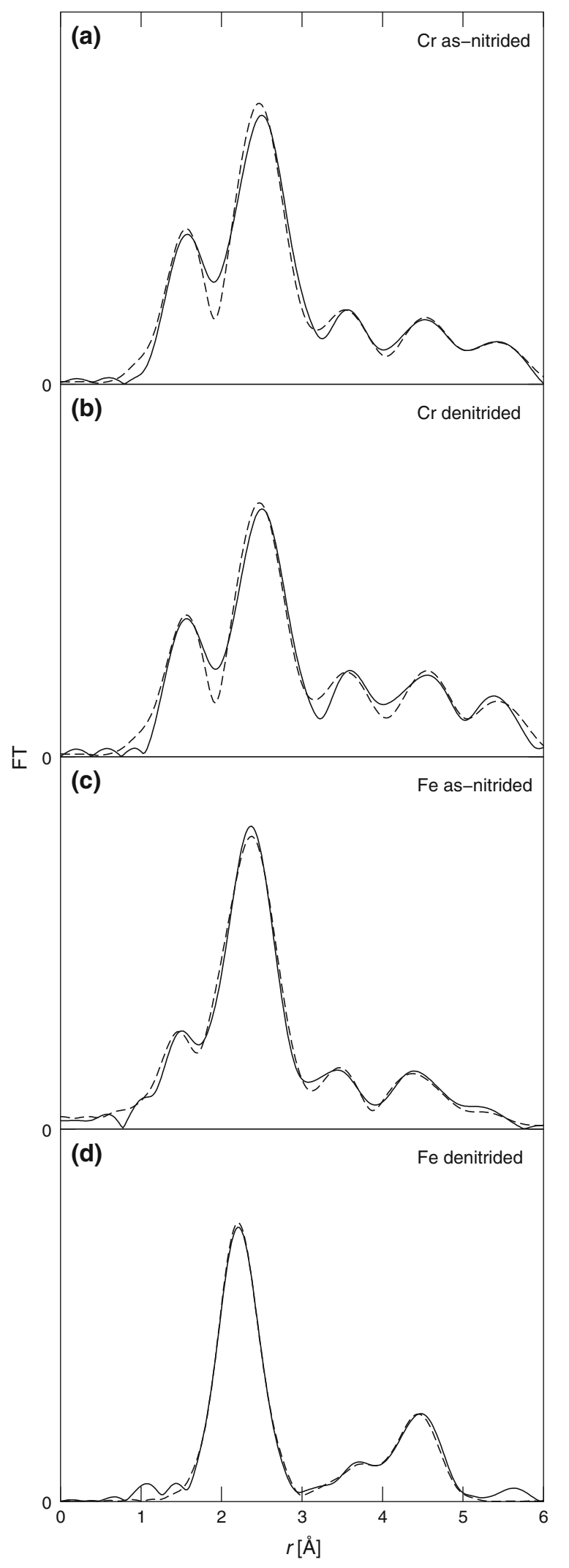

Fig. 5 Pseudo radial distribution functions obtained by Fourier Transformation of the EXAFS in Figs. 3 and 4 (full drawn line) and the models described in Tables 1 and 2 (dashed line) that one-third of the $\mathrm{Cr}$ atoms is present in expanded austenite. However, considering that 6 extra parameters were added and that the cell constant of the $\mathrm{CrN}$ phase still refined to $4.12-4.13 \AA$ while the values of $\sigma_{\mathrm{j}}^{2}$ obtained for the expanded austenite phase were extremely large, it must be concluded that the two-phase model does not constitute a significant improvement to the single $\mathrm{CrN}$ phase when it comes to describing the Cr EXAFS data.

Iron

The local structure of $\mathrm{Fe}$ in the as-nitrided sample is found to be that of expanded austenite (Fig. 5c). Refining the coordination number of $N$ around the central $\mathrm{Fe}$ atom and constraining $N_{\mathrm{j}}$ of the $\mathrm{Fe}-\mathrm{Fe}-\mathrm{N}$ multiple scattering path to follow, the residual dropped from 14.5 to the final value of 11.9. For the $\mathrm{Fe}-\mathrm{N}$ path the value of $N_{\mathrm{j}}=1.9$, corresponding to $y_{\mathrm{N}}=0.32$, resulted. The values of $N_{\mathrm{j}}, r_{\mathrm{j}}$ and $\sigma_{\mathrm{j}}^{2}$ determined by EXAFS do not correspond exclusively to the expanded austenite phase, they also reflect the two iron nitride phases that were identified with the XRD analysis. This is the reason why the values of $\sigma_{\mathrm{j}}^{2}$ are extremely large, except for the paths containing $N$ where they correlate with the low occupancy. However, the local structures of the iron nitrides are so similar to that of expanded austenite that the contributions from the individual phases cannot be resolved in a multi-phase refinement due to correlations. Instead it should be noted that the obtained nitrogen occupancy and interatomic distances correspond nicely to an average over all three phases; especially if it is assumed that a fraction of the metal atoms in the expanded austenite phase in fact concerns $\mathrm{Cr}$.

The FT of the Fe data for the denitrided sample (Fig. 5d) does not contain the first $\mathrm{Fe}-\mathrm{N}$ peak. According to the Rietveld refinements the major phase is martensite, tetragonally distorted ferrite, with an almost negligible $(c / a=1.01)$ tetragonal distortion. For this reason, and because the process of correlating distances is more straightforward for cubic structures, ferrite was used for fitting the EXAFS data. Nitrogen-free austenite was used as the second phase and the relative abundance of ferrite and austenite was set to 42:58 as determined from the Rietveld refinements. The first $\mathrm{Fe}-\mathrm{Fe}$ distances of ferrite and austenite are very similar, so the values of $\sigma_{\mathrm{j}}^{2}$ for these paths correlate strongly. Tentatively, it was chosen to set $\sigma_{1}^{2}$ (austenite) $=3 \sigma_{1}^{2}$ (ferrite), and this turned out to give consistent $\sigma_{\mathrm{j}}^{2}$ values. The larger $\sigma_{\mathrm{j}}^{2}$ values obtained for austenite are a consequence of the fact that the two different austenitic phases observed in XRD are only modelled as one phase in the EXAFS refinements to limit the number of correlating parameters. The quality of the EXAFS fit strongly supports the model suggested by XRD. 


\section{Discussion}

Nitriding of thin stainless steel flakes for $24 \mathrm{~h}$ resulted in the development of several phases. In addition to nitrogen expanded austenite also $\mathrm{CrN}, \gamma^{\prime}-\mathrm{Fe}_{4} \mathrm{~N}_{1-X}$ and $\varepsilon-\mathrm{Fe}_{2} \mathrm{~N}_{1-X}$ develop, ${ }^{1}$ yielding a total nitrogen content in the as-nitrided sample of $0.45-0.51$ nitrogen atoms per metal atom (Table 4). This is significantly lower than the maximum solubility of $y_{\mathrm{N}}=0.61$ for nitrogen expanded austenite, and it is thought to be a consequence of the formation of nitride phases during nitriding. For thermodynamic reasons $\mathrm{CrN}$ is expected to form prior to the iron-based nitrides $\gamma^{\prime} \mathrm{Fe}_{4} \mathrm{~N}_{1-X}$ and $\varepsilon-\mathrm{FeN}_{1-X}$. The reason that $\mathrm{CrN}$ development is observed in the present samples could be associated with the relatively large surface area of the flakes. $\mathrm{CrN}$ will most probably start to develop at the surface, where no strain energy effects are experienced upon nucleation; this surface effect is expected to be most pronounced for incoherent precipitates. Accordingly, in the centre of the flakes expanded austenite could still be present. The development of $\mathrm{CrN}$ retracts $\mathrm{Cr}$ atoms from solid solution in the austenite phase and effectively yields an austenitic structure rich in $\mathrm{Fe}$ and $\mathrm{Ni}$. Subsequently, the iron-based nitrides $\gamma^{\prime}-\mathrm{Fe}_{4} \mathrm{~N}_{1-X}$ and $\varepsilon-\mathrm{Fe}_{2} \mathrm{~N}_{1-X}$ develop in the $\mathrm{Cr}$ depleted austenite as nitriding is carried out under conditions resulting in a high nitriding potential. Consequently, the mass fraction of nitrogen expanded austenite is lowered to 0.388 .

After denitriding, the nitrogen content in expanded austenite is significantly lowered, resulting in a $y_{\mathrm{N}}$ of approximately 0.12 provided that the known linear relationship between nitrogen content and lattice parameter of expanded austenite as determined in Ref. [6] can be extrapolated to this concentration range. This means that loosely bound nitrogen has been retracted and that only tightly bound nitrogen resides in the expanded austenite; ostensibly the lower content of chromium in solid solution is responsible for the lower nitrogen content of tightly bound nitrogen, as compared to expanded austenite without $\mathrm{CrN}$ precipitates. Presuming $\mathrm{Cr}: \mathrm{N}=1: 1$ as observed in Ref. [6], the remaining $\mathrm{Cr}$ content in expanded austenite amounts to 12 at.\%. The iron-based nitrides $\gamma^{\prime}$ and $\varepsilon$ present in the as-nitrided sample have disappeared and instead a nitrogen free austenite phase has developed in the $\mathrm{Cr}$ depleted part of the sample.

The change in phase constitution of the sample is reflected in the Fe EXAFS data, where the chemical surroundings of the $\mathrm{Fe}$ atoms are found to change after denitriding, which for a large part can be attributed to the reduction of the formed iron nitrides. The presence of both

\footnotetext{
${ }^{1}$ It is likely that $\mathrm{Ni}$ and $\mathrm{Cr}$ dissolve in the iron nitrides $\gamma^{\prime}$ and $\varepsilon$, respectively.
}

expanded austenite and virtually nitrogen-free austenite is an immediate consequence of the precipitation of $\mathrm{CrN}$, which obviously proceeds inhomogeneously (preferably at the surface; see above). In the adjacent matrix, the $\mathrm{Cr}$ content is lowered, which concomitantly lowers the nitrogen solubility. As a consequence of mechanical processing for sample preparation a large fraction of the sample is converted into martensite with relatively low nitrogen contents. The formation of martensite is more likely to occur in regions with low nitrogen content. Disregarding the presence of nitrides, a large fraction of nitrogen in the expanded austenite can be retracted and nitrogen residing in Fe-based nitrides in the as-nitrided sample can be fully retracted. The fraction of nitrogen which resides in the material after exposure to flowing hydrogen consists of the nitrogen bound as $\mathrm{CrN}$ and the non-retractable nitrogen associated with expanded austenite.

Rietveld refinements indicated that the mass fractions of CrN by XRD are 0.112 and 0.135 for the as-nitrided and denitrided sample, respectively, while the corresponding theoretical values for the mass fractions of $\mathrm{CrN}$ are 0.19 and 0.205 if all $\mathrm{Cr}$ atoms would reside in stoichiometric $\mathrm{CrN}$ precipitates. This implies that only 63 and $66 \%$ of the chromium atoms are associated with $\mathrm{CrN}$ precipitates that diffract independently from the matrix in XRD analysis for the as-nitrided and denitrided samples, respectively. The remaining $\mathrm{Cr}$ content is associated with other phases. For the as-nitrided sample a fraction of the chromium atoms is expected to be found in the expanded austenite phase and in the iron nitrides, most likely in $\varepsilon-\mathrm{Fe}_{2} \mathrm{~N}_{1-X}$. For the denitrided sample, the remaining fraction of $\mathrm{Cr}$ should be found in the expanded austenite and in the deformationinduced martensite phase. However, according to EXAFS investigations the majority of $\mathrm{Cr}$ atoms is associated with a nitrogen-chromium bond distance comparable to that of the chemical compound $\mathrm{CrN}$ in both the as-nitrided and denitrided sample. Hence, it is likely that more than 63$66 \%$ of the chromium atoms should be bound as $\mathrm{CrN}$. This implies that a fraction of the formed $\mathrm{CrN}$ diffracts coherently with one of the other phases (e.g. expanded austenite) and cannot be identified with XRD. Only with short-rangeorder techniques, such as EXAFS these atoms can be observed. The fact that almost all chromium atoms are associated with $\mathrm{CrN}$ is in contradiction with the traditional interpretation of the formation of expanded austenite, which assumes that $\mathrm{Cr}$ is available in the austenite lattice for "trapping" of nitrogen without forming (chromium) nitrides. It is evident that expanded austenite still forms with high nitrogen contents even though the austenite matrix is apparently depleted in chromium. An explanation to these observations is hypothesised in the following.

Nitriding of ferritic steels alloyed with a low content of strong nitride formers viz. $\mathrm{Ti}, \mathrm{V}, \mathrm{Cr}, \mathrm{Mo}$, etc. can give rise to 
a significant hardening effect and abnormal nitrogen/metal ratios, higher than what can be accounted for by equilibrium metal nitride precipitates. This has been attributed to the formation of so-called mixed substitutional-interstital atom clusters (MSIAC, cf. GP zones) [10, 17] or coherent platelets (nitrides) [18] of nitrogen and strong nitride formers. A matrix containing MSIAC or coherently diffracting nitride platelets, i.e. a non-random solid solution, has the same unit cell as a random solid solution of the same concentration and only when precipitation occurs does the lattice parameter change to that of the depleted solid solution [10]. Hence MSIAC or coherent platelets diffract coherently with the matrix and conventional XRD analysis does not reveal their presence, only an increased lattice parameter. Consequently, XRD analysis cannot distinguish between MSIAC and coherent nitride platelets as the diffraction effects are identical. The prerequisites for MSIAC or coherent nitride platelet development are (i) a large driving force for nitride formation, (ii) a low interfacial energy for the platelet morphology and (iii) low strain energy upon MSIAC or coherent nitride platelet development (cf. the interaction parameter defined in Ref. [18]). MSIAC have also been suggested to occur in nitrided austenitic $\mathrm{Fe}-35 \mathrm{Ni}-\mathrm{V}, \mathrm{Nb}$ alloys at temperatures as high as 873-973 K [19].

In the present investigation the analogy to MSIAC or nitride platelet formation is straightforward:

i. nitride formation is promoted by a large driving force [4];

ii. the lattice misfit between expanded austenite (with at least $\mathrm{Cr}: \mathrm{N}=1: 1$ ) is less than $10 \%$ and decreases with increasing nitrogen content to $3 \%$ for $\mathrm{Cr}: \mathrm{N}=1: 3$ (cf. [6]). At the interface between $\mathrm{CrN}$ and expanded austenite ferrite could develop to lower the misfit between platelet and matrix even more;

iii. The volume misfit between MSIAC/coherent nitride platelet and matrix is relatively small and they have a disc-shape morphology, so limited strain energy effects are expected.

X-ray diffraction can only account for a part of the $\mathrm{Cr}$ atoms as $\mathrm{CrN}$, whereas the remaining part does not give independent diffraction. This could suggest the presence of MSIAC or coherent nitride platelets in austenitic stainless steel, thus leading to an enhanced solubility of nitrogen. MSIAC or coherent nitride platelets of $\mathrm{Cr}$ and $\mathrm{N}$ could lead to abnormal solubility of nitrogen in austenite (Fe surroundings). The ratio of $\mathrm{N}$ to $\mathrm{Cr}$ and $\mathrm{Mo}$ is approximately $3: 1$ in expanded austenite [6], which is somewhat similar to the ratios found for low-alloyed ferritic and austenitic alloys $[10,15]$.

Unfortunately, the present data are flawed by the fact that the expanded austenite was not obtained uniformly throughout the sample, but is influenced by the presence of both nitrides and mechanically induced martensite phases. In order to verify the validity of the above hypothesis that MSIAC/coherent nitride platelets are present and to distinguish between MSIAC and coherent nitride platelets, further EXAFS work on homogeneous samples is necessary.

\section{Conclusions}

Low temperature nitrided and denitrided micrometer-sized AISI 316 stainless steel flakes were investigated by EXAFS and XRD analysis. Nitrogen expanded austenite was obtained in both the as-nitrided and denitrided samples, together with several other phases including $\mathrm{CrN}$. The local structure of the $\mathrm{Cr}$ atoms was largely unaffected by denitriding in flowing hydrogen, whereas the $\mathrm{Fe}$ atoms experienced a change in chemical surroundings. Furthermore the local structure of the majority of $\mathrm{Cr}$ atoms was found to conform to the bond length of the chemical compound $\mathrm{CrN}$, although only a fraction of the $\mathrm{Cr}$ atoms could be detected as $\mathrm{CrN}$ with XRD analysis. A possible explanation for this observation is that part of the chromium nitrides diffracts coherently with the matrix or is present as mixed substitutional-interstitial atom clusters, analogous to nitrided ferritic alloys containing nitride-forming alloying elements.

Acknowledgement Financial support of the Danish Research Council for Technology and Production Sciences under grant 274-050230 is gratefully acknowledged.

\section{References}

1. Bell T, Akamatsu K (eds) (2000) Stainless Steel 2000-Proceedings of the 1st International Conference on 'Thermochemical Surface Engineering of Stainless Steel', Osaka, Japan, November 2000, Maney Publishing

2. Sun Y, Li X, Bell T (1999) Mater Sci Technol 15:1171

3. Cao Y, Ernst F, Michal GM (2003) Acta Mater 51:4171. doi: 10.1016/S1359-6454(03)00235-0

4. Christiansen T, Somers MAJ (2005) Surf Eng 21:445. doi: $10.1179 / 174329405 \times 68597$

5. Czerwiec T, He H, Weber S, Dong C, Michel H (2006) Surf Coat Tech 200:5289. doi:10.1016/j.surfcoat.2005.06.014

6. Christiansen T, Somers MAJ (2006) Metall Mater Trans A 37:675. doi:10.1007/s11661-006-0039-5

7. Oda K, Kondo N, Shibata K (1990) ISIJ Int 30(8):625. doi: 10.2355/isijinternational.30.625

8. Kizler P, Frommeyer G, Rosenkranz R (1994) Z Metallkd 85:705

9. Munoz-Paez A, Peruchena JIF, Espinós JP, Justo Á, Castaneda F, Díaz-Moreno S et al (2002) Chem Mater 14:3220. doi:10.1021/ $\mathrm{cm} 025568 \mathrm{~g}$

10. Jones DM, Stephenson A, Hendry A, Jack KH (1979) Conf Strenght Met Alloys 5:737

11. Oddershede J, Christiansen TL, Ståhl K (2008) J Appl Cryst 41:537. doi:10.1107/S00218898080005943

12. Cheng L, Böttger A, de Keijser TT, Mittemeijer EJ (1990) Scr Metall Mater 24:509. doi:10.1016/0956-716X(90)90192-J 
13. Carlson S, Clausen M, Gridneva L, Sommarin B, Svensson C (2006) J Synchrotron Radiat 13:359. doi:10.1107/S09090495060 25611

14. Ressler T (2004) WinXAS Ver. 3.10

15. Zabinsky SI, Rehr JJ, Aukudinov A, Albers RC, Eller MJ (1995) Phys Rev B 52:2995. doi:10.1103/PhysRevB.52.2995

16. Venables JA (1962) Philos Mag 7:35. doi:10.1080/1478643 6208201856
17. Jack H (1973) Proc Heat Treat 73:39

18. Somers MAJ, Lankreijer RM, Mittemeijer EJ (1989) Philos Mag A 59(2):353. doi:10.1080/01418618908205064

19. Driver JH, Handley JR, Jack KH (1972) Scand J Metallurgy $1: 211$ 